\title{
Tuberculosis de la cadera. Presentación de un caso y revisión de la literatura
}

\author{
María F. Villafañe, Marcelo Corti, Omar Palmieri y Maximiliano Castro
}

\footnotetext{
Hospital de Infecciosas F. J. Muñiz, Buenos Aires, Argentina. División B, VIH/SIDA (MFV, M Servicio de Ortopedia y Traumatología (M. Castro) Facultad de Medicina, Universidad de Buenos Aires, Argentina.

Departamento de Medicina Orientación Enfermedades Infecciosas (OP)
}

Recibido: 3 de noviembre de 2014 Aceptado: 10 de agosto de 2015

Correspondencia a: María F. Villafañe mfioti@intramed.net

\section{Introducción}

E n la actualidad, la tuberculosis (TB) ocupa el primer lugar entre las infecciones oportunistas marcadoras del síndrome de inmunodeficiencia adquirida (SIDA). El aumento en la incidencia de las formas extrapulmonares de la enfermedad se halla estrechamente vinculado con la co-infección con el virus de la inmunodeficiencia humana (VIH). En Argentina, 10\% de los casos de TB en la población general corresponden a las formas extrapulmonares; en contraposición, en la población con infección por VIH, la incidencia de la TB extrapulmonar supera el $35 \%{ }^{1}$.

La coxoartritis, también llamada coxitis tuberculosa o tuberculosis (TB) coxo-femoral, constituye junto con la espondilodiscitis tuberculosa o mal de Pott y el denominado tumor blanco de la rodilla, una de las localizaciones más frecuentes de la infección fímica del esqueleto ${ }^{1}$. Puede iniciarse en la membrana sinovial (sinovitis tuberculosa) o en el hueso (osteítis tuberculosa). Por lo general, es unilateral (monoartritis) y desde el punto de vista histopatológico se caracteriza por ser una osteoartritis caseosa $\mathrm{s}^{2,3}$.

Se presenta el caso clínico de un paciente con infección por VIH, que desarrolló una TB de la cadera en el contexto de su inmunodeficiencia.

\section{Caso clínico}

Varón de 21 años, oriundo de la provincia de Buenos Aires, con el antecedente de infección por VIH adquirida por transmisión vertical, y abandono de varios tratamientos antirretrovirales de gran actividad (TARGA). Se internó por un síndrome febril de tres semanas de evolución, asociado a tos y pérdida de peso de aproximadamente $10 \mathrm{~kg}$.

Al examen físico el paciente se encontraba febril, en regular estado general y con palidez de piel y mucosas. Se palpaba una hepato-esplenomegalia indolora y la auscultación pulmonar presentaba una disminución generalizada del murmullo pulmonar en ambos campos pulmonares.

La radiografía de tórax mostró una opacidad parahiliar y basal derecha de aspecto neumónico (Figura 1). Los resultados de los exámenes de laboratorio al ingreso fueron: eritro-sedimentación $>140 \mathrm{~mm} 1^{\circ}$ hora, hematocrito $21 \%$, hemoglobina $6,6 \mathrm{~g} / \mathrm{L}$, leucocitos 4.400 cél $/ \mathrm{mm}^{3}$, plaquetas 40.000 cél $/ \mathrm{mm}^{3}$, concentración de protrombina $68 \%$, urea $16 \mathrm{mg} / \mathrm{dL}$, creatinina $0,9 \mathrm{mg} / \mathrm{dL}$, transaminasas GOT 61 UI/L, GPT $20 \mathrm{UI} / \mathrm{L}$, fosfatasas alcalinas: $185 \mathrm{U} / \mathrm{L}$ y láctico deshidrogenasa: $400 \mathrm{U} / 1$. El recuento de linfocitos T CD4 fue de 21 cél $/ \mathrm{mm}^{3}(8 \%)$.

Se tomaron muestras de expectoración para la identificación de bacterias de crecimiento corriente, micobacterias y hongos. En el examen directo mediante la técnica de Zielh-Neelsen, se observaron 10 bacilos ácido-alcohol resistentes (BAAR) por cada 10 campos. La ecotomografía abdominal confirmó la existencia de hepato-esplenomegalia y de múltiples adenopatías hipoecogénicas en el retroperitoneo, en relación a la vena cava inferior y al ligamento hepato-duodenal. También se observaron imágenes hipoecogénicas en el bazo, mesenterio y retroperitoneo. 
Con el diagnóstico de una probable tuberculosis se inició tratamiento con isoniacida, rifampicina, pirazinamida y etambutol en forma diaria y en dosis habituales.

A la semana de iniciada la terapia el paciente comenzó a referir dolor en la articulación coxo-femoral izquierda que se irradiaba hacia el muslo, produciendo impotencia funcional y posición antiálgica en semiflexión. Presentaba dolor a la palpación de dicha articulación coxofemoral con imposibilidad de extensión activa y pasiva de la extremidad inferior izquierda. La ecotomografía mostró una moderada cantidad de líquido articular y en la tomografía axial computarizada (TAC) se observó una imagen radiolúcida, redondeada, en la unión de la cabeza y el cuello femoral, con solución de continuidad hacia la cortical ósea. La cavidad acetabular y la cabeza femoral estaban respetadas igual que la sínfisis pubiana y las ramas isquio e ilio-pubianas. En la cavidad articular se observó un moderado volumen de líquido (Figuras 2, 3, 4).

Se realizó una artrocentesis obteniéndose un material sero-hemático. Se enviaron muestras para la identificación de bacterias de crecimiento común, micobacterias y hongos. El examen directo mediante la técnica de Zielh-Neelsen, mostró cinco a nueve BAAR por cada 100 campos de observación.

Además del tratamiento antituberculoso se agregaron analgésicos y corticoesteroides. Siete días después, el paciente presentó una evolución favorable, con paulatina recuperación de la movilidad del miembro inferior izquierdo, apoyada con soporte kinésico.

Los cultivos de las muestras tanto de esputo como del líquido articular, permitieron identificar Mycobacterium

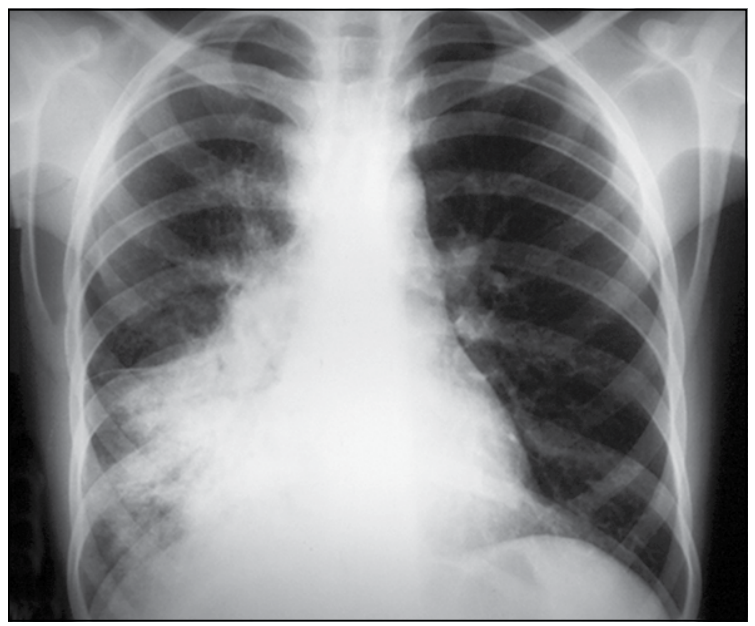

Figura 1. Radiografía de tórax. Opacidad homogénea parahiliar y basal derecha de aspecto neumónico. tuberculosis con susceptibilidad conservada a los fármacos prescriptos.

A los 30 días de tratamiento se comprobó una marcada mejoría en las lesiones pulmonares (Figura 5) y el examen directo de expectoración de control fue negativo para BAAR.

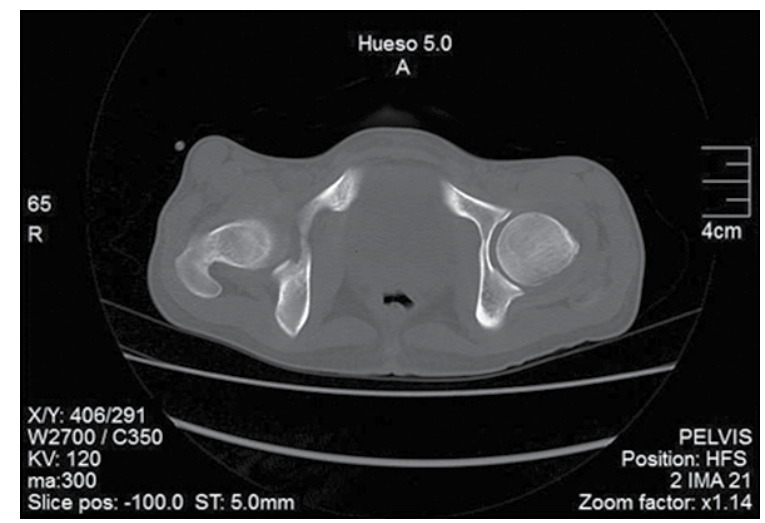

Figura 2. Tomografía computarizada de cadera izquierda. Imagen radiolúcida, redondeada, en la unión de la cabeza y el cuello femoral con solución de continuidad hacia la cortical ósea.

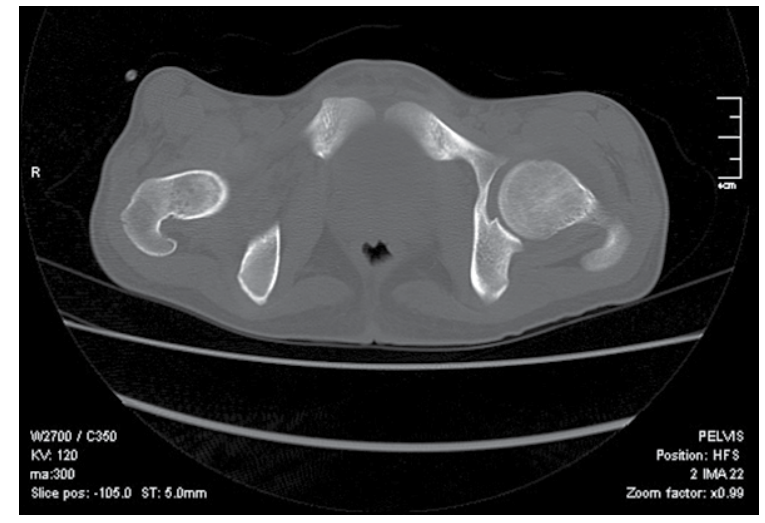

Figura 3. Tomografía computarizada de cadera izquierda. Moderado volumen de líquido en la cavidad articular.

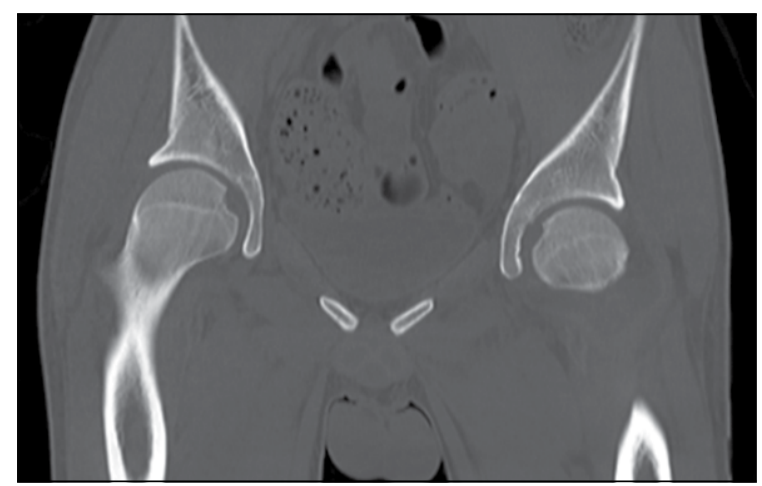

Figura 4. Tomografía computarizada de cadera izquierda. Imagen de abombamiento de la cápsula articular como signo de derrame articular. 


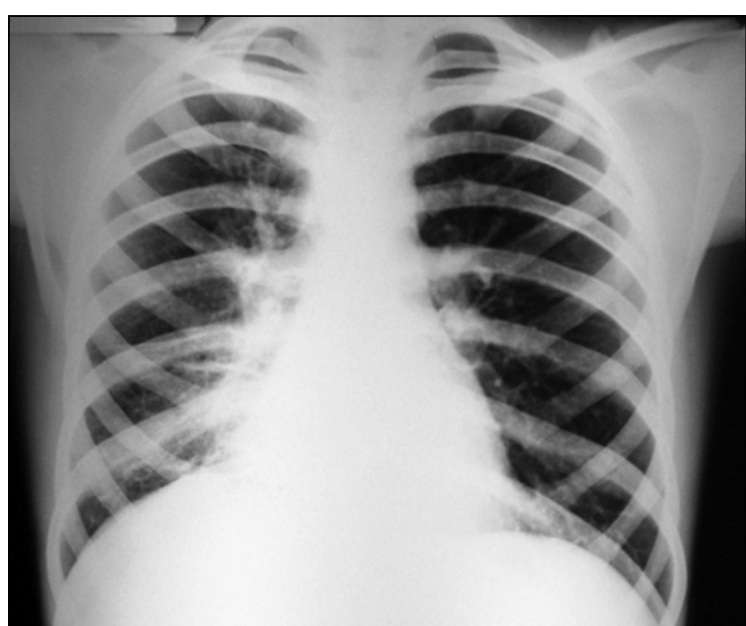

Figura 5. Radiografía de tórax con evidente mejoría de las imágenes pulmonares, un mes después de iniciada la terapia antituberculosa.

\section{Discusión}

Si bien la TB pulmonar es la forma más común de presentación de esta enfermedad en los pacientes infectados por VIH, en aquellos casos de enfermedad avanzada e inmunodeficiencia grave $\left(\mathrm{CD} 4<200 \mathrm{cé} / \mathrm{mm}^{3}\right)$, las formas extrapulmonares son mucho más frecuentes, con una incidencia de 4,6 a 80\%; según las distintas series ${ }^{1}$.

Por otra parte, si bien en la población general las formas extrapulmonares se presentan habitualmente en ausencia de compromiso pulmonar, en la población infectada por el retrovirus se comprueba con frecuencia el compromiso concomitante pulmonar y extrapulmonar ${ }^{4}$. Dentro de la formas extrapulmonares asociadas al VIH, las más frecuentes son la TB diseminada, genitourinaria, ganglionar, pleural, del sistema nervioso central (meningitis o parenquimatosa), intraabdominal (linfadenitis, peritonitis o gastrointestinal) y la osteoarticular ${ }^{4}$.

La inmunodepresión se asocia, con frecuencia, con la localización osteoarticular de la TB diseminada ${ }^{5}$. La localización de la infección tuberculosa en el esqueleto es una complicación rara de la TB diseminada $\mathrm{y}$, en los pacientes adultos, compromete en orden de frecuencia la columna vertebral, la cadera y la rodilla. El 50\% de las formas osteo-articulares de la enfermedad afectan a la columna vertebral ${ }^{6,7}$. El compromiso óseo suele ser la consecuencia de la diseminación hematógena de $M$. tuberculosis desde un foco pulmonar.

Mycobacterium tuberculosis se localiza en los elementos anatómicos constituyentes de la articulación coxo-femoral en íntima relación con los vasos y la membrana sinovial. De esta manera, se determinan las dos formas clínicas principales. La primera denominada yuxta-articular, en la cual el bacilo no invade la luz ni la sinovial y la segunda denominada articular, con invasión de la membrana sinovial y el hueso ${ }^{3}$.

La infección tuberculosa de la cadera es un proceso de diagnóstico difícil que suele afectar a adultos de mediana edad y ancianos, habitualmente a partir de la diseminación hematógena del bacilo desde un foco pulmonar o renal. Las lesiones tuberculosas urogenitales co-existen con el compromiso osteo-articular en 20 a $45 \%$ de los casos ${ }^{7}$. El comienzo es insidioso e inespecífico, por lo cual el diagnóstico generalmente se retrasa.

La coxalgia es el síntoma principal y el que motiva la consulta; se acompaña de impotencia funcional y se irradia a la región inguinal o glútea. Al comienzo es leve a moderada, pero se incrementa lentamente a través de las semanas o meses. El primer hallazgo clínico puede ser un derrame articular asociado a hipertrofia del tejido sinovial (sinovitis), lo cual se manifiesta clínicamente como derrame articular, con o sin adelgazamiento del tejido sinovial. Cuando la lesión progresa compromete los movimientos de extensión, aducción y rotación interna de la cadera, como pudo evidenciarse en nuestro paciente.

En el estudio radiológico se observa un aumento de volumen de los tejidos blandos y una osteopenia difusa, sin anormalidades focales. Los primeros cambios óseos son erosiones marginales, evidentes en la radiografía. Posteriormente se presenta una erosión del cartílago articular y del hueso sub-condral, lo que origina la pérdida del espacio articular ${ }^{6}$.

Existen dos patrones histopatológicos básicos de la enfermedad: granulomatoso y exudativo (caseoso). La forma granulomatosa se caracteriza por la formación de tubérculos sub-sinoviales con exudado fibrinoso que diseca el cartílago e infiltra el hueso esponjoso subcondral, generando las caries óseas. Estas son lesiones en sacabocado localizadas en los márgenes de la articulación, con gran reacción fibroblástica. La forma caseosa es más agresiva, y se caracteriza por la presencia de lesiones osteolíticas con formación de caseum que destruye la articulación y conduce a la anquilosis ${ }^{8}$. Esta forma predomina en adultos con deterioro de la respuesta inmune, como en el paciente que presentamos.

La resonancia magnética (RM) es el método de elección para el diagnóstico precoz, pues permite detectar las lesiones iniciales como el edema capsular, el derrame articular y las lesiones óseas sub-condrales 9 .

En el estudio anátomo-patológico obtenido por una biopsia de la membrana sinovial se observa el clásico granuloma tuberculoso y, en ocasiones, la coloración de Ziehl-Neelsen muestra la presencia de BAAR ${ }^{10}$.

El diagnóstico se confirma con la detección de $M$. tuberculosis en las muestras obtenidas del líquido articular o de la biopsia de la membrana sinovial a través del examen directo y el cultivo, con el correspondiente antibiograma. 
Diversas técnicas moleculares se encuentran disponibles para el diagnóstico de la TB, con algunas ventajas sobre los métodos tradicionales como su rapidez y mayor sensibilidad y especificidad en aquellas muestras con baciloscopia positiva. Entre las ventaja de su uso, también puede citarse, la posibilidad de detectar genes implicados en la resistencia a los fármacos, y su utilidad para estudios de epidemiología molecular. Algunas desventajas que pueden señalarse son su baja sensibilidad y especificidad en muestras con baciloscopia negativa y en las formas extrapulmonares, además de la posibilidad de contaminación cruzada durante el procedimiento de extracción de los ácidos nucleicos ${ }^{10}$.

El tratamiento de los pacientes co-infectados con VIH y TB presenta algunas características que lo hacen particularmente complejo. Existe mayor riesgo de reacción alérgica y toxicidad a los fármacos antituberculosos y mayor dificultad para lograr una adecuada adherencia a ambas terapias. Los esquemas de terapia antituberculosa recomendados siguen, en general, los mismos principios que para aquellos pacientes sin infección por el retrovirus. El momento óptimo para iniciar la terapia antirretroviral de gran actividad (TARGA) debe balancear el riesgo de añadir toxicidad y posibles interacciones farmacológicas, contra el riesgo de diferir el inicio y prolongar el período de inmunosupresión. Las reacciones paradojales al tratamiento antituberculoso son más frecuentes en individuos con infección por VIH y, además, durante las primeras semanas y hasta tres meses después de iniciada la TARGA se comprueba un riesgo incrementado de desarrollar el síndrome inflamatorio de reconstitución inmune (SIRI). Este fenómeno se debería a la rápida restauración de la inmunidad celular patógeno-específica asociada con la TARGA y puede manifestarse como el agravamiento de una TB que ya se encontraba en tratamiento con buena respuesta inicial o bien como la manifestación clínica de una infección tuberculosa latente. Para disminuir el riesgo del SIRI, se recomienda la indicación de la TARGA luego de dos semanas de iniciado el tratamiento antituberculoso ${ }^{11}$.

Nuestro paciente presentó una TB diseminada con compromiso pulmonar, abdominal (ganglionar y visceral) y osteo-articular, en relación con su enfermedad de base y grave inmunodeficiencia.

Se trata de un caso poco frecuente por la articulación comprometida y la confirmación del diagnóstico se realizó a partir del examen directo y del cultivo del líquido sinovial.

\section{Resumen}

La tuberculosis osteo-articular es una localización infrecuente de las formas diseminadas de la enfermedad tuberculosa. Su incidencia, según las distintas series, oscila entre $10 \%$ y el $20 \%$. Su patogenia es la diseminación por vía hematógena. La coxitis o afección tuberculosa de la cadera representa menos de $10 \%$ de las TB osteoarticulares. El diagnóstico se confirma con la detección de Mycobacterium tuberculosis en las muestras obtenidas del líquido articular o la biopsia de la membrana sinovial a través del examen directo y el cultivo. Presentamos un paciente con infección por el virus de la inmunodeficiencia humana (VIH) que desarrolló una TB diseminada con compromiso de la cadera en el contexto de su inmunodeficiencia.

\section{Referencias bibliográficas}

1.- Metta H, Corti M, Ambroggi M. Aspectos epidemiológicos, clínicos, diagnósticos y terapéuticos de la tuberculosis extrapulmonar en pacientes con infección por el virus de la inmunodeficiencia humana. Rev Panam Infectol 2006; 8: 21-6.

2.- Pertuiset E, Beaudreuil J, Horusitzky A, Lioté F, Kemiche F, Richette P, et al. Aspects epidemiologiques de la tuberculose ósteoarticulaire de 1'adulte. Presse Med 1997; 26: 311-5.

3.- Sankaran B. Tuberculosis of bones and joints. Ind J Tub 1993; 40: 109-18.

4.- Kwan C K, Ernst J D. HIV and tuberculosis: a deadly human syndemic. Clin Microbiol Rev
2011; 24: 351-76.

5.- Panisello Sebastiá J J, Martínez Martín A, Cuenca Espíerrez J, Peguero Bona A, Herrero Barcos L. Artritis tuberculosa de cadera. Planteamiento terapéutico de dos situaciones diferentes. Rev Esp Cirug Osteoarticular 2000; 35: $386-8$

6.- Pertuiset E, Beaudreuil J, Lioté F, Horusitzky A, Kemiche F, Richette P, et al. Spinal tuberculosis in adults. A study of 103 cases in a developed country, 1980-1994. Medicine (Baltimore) 1999; 78: 309-20.

7.- Palmero D J, Simboli N, Alberti F A, Francos J L, Güemes Gurtubay J L, Ochoa E J, et al. Coxitis por Mycobacterium tuberculosis multirresistente en un paciente HIV negativo. Medicina (Buenos Aires) 2000; 60: 357-60.
8.- Rodríguez Messina A F, Flores Razo M A, Fernández de Lara Castilla L G, Cariño Cepeda C, Cordero Rivera E A, Cruz Guzmán M A, et al. Infección de cadera por Mycobacterium tuberculosis. Rev Esp Med Quir 2014; 19: 1138.

9.- Midri M, Filosto L, Lo Casto A, Masciocchi C. La risonanza magnetica nello studio de lla coxite tubercolare. Radio Med (Torino) 1992; 83: 38-42.

10.- Alcaide F. ¿Qué aporta la biología molecular al diagnóstico de la tuberculosis? Enferm Infecc Microbiol Clin 2009; 27: 493-5.

11.- Corti M E, Palmero D J. Tratamiento antirretroviral en pacientes con SIDA y micobacteriosis. Medicina (Buenos Aires) 2005; 65: 353-6. 